\title{
BMJ Open Physical activity and concussion risk in youth ice hockey players: pooled prospective injury surveillance cohorts from Canada
}

\author{
Tracy A Blake, ${ }^{1,9,2}$ Patricia K Doyle-Baker, ${ }^{1,3}$ Brian L Brooks, ${ }^{4,5,6,7}$ \\ Luz Palacios-Derflingher, ${ }^{1}$ Carolyn A Emery ${ }^{1,6,7,8}$
}

To cite: Blake TA, DoyleBaker PK, Brooks BL, et al. Physical activity and concussion risk in youth ice hockey players: pooled prospective injury surveillance cohorts from Canada. BMJ Open 2018;8:e022735. doi:10.1136/ bmjopen-2018-022735

\section{- Prepublication history and} additional material for this paper are available online. To view these files, please visit the journal online (http://dx.doi. org/10.1136/bmjopen-2018022735).

Received 6 March 2018 Revised 20 July 2018 Accepted 26 July 2018
Check for updates

(C) Author(s) (or their employer(s)) 2018. Re-use permitted under CC BY-NC. No commercial re-use. See rights and permissions. Published by BMJ.

For numbered affiliations see end of article.

Correspondence to Dr Tracy A Blake;

tracyablakeptphd@gmail.com

\section{ABSTRACT}

Objective To examine the association between meeting physical activity (PA) volume recommendations and concussion rates in male ice hockey players aged 11-17 years.

Design Pooled prospective injury surveillance cohort data from the 2011-2012, 2013-2014 and 2014-2015 youth ice hockey seasons.

Participants Male Alberta-based Pee Wee (aged 11-12 years), Bantam (aged 13-14 years) and Midget (aged 15-17 years) ice hockey players participating in any of the three cohorts were eligible $(n=1726)$. A total of 1208 players were included after the exclusion criteria were applied (ie, players with new/unhealed injuries within 6 weeks of study entry, missing 6-week PA history questionnaires, missing game and/or practice participation exposure hours, players who sustained concussions when no participation exposure hours were collected).

Outcome measures Dependent variable: medically diagnosed concussion. Independent variable: whether or not players' self-reported history of PA (ie, hours of physical education and extracurricular sport participation) met the Canadian Society of Exercise Physiology and Public Health Agency of Canada recommendation of one hour daily during the 6 weeks prior to study entry (ie, 42 hours or more).

Results The PA volume recommendations were met by $65.05 \%$ of players who subsequently sustained concussions, and $75.34 \%$ of players who did not sustain concussions. The concussion incidence rate ratios (IRR) reflect higher concussion rates in players who did not meet the PA volume recommendations vs. players who met the PA volume recommendations among Pee Wee players (IRR 2.94 95\% Cl 1.30 to 6.64), Bantam players (IRR 2.18, 95\% Cl 1.21 to 3.93) and non-elite players aged 11-14 years (IRR $2.45,95 \% \mathrm{Cl} 1.33$ to 4.51 ).

Conclusion and relevance The concussion rate of players who did not meet the Canadian PA volume recommendations was more than twice the concussion rate of players who met recommendations among male Pee Wee players, Bantam players and non-elite level players. Further exploration of the impact of public health PA recommendations in a sport injury prevention context is warranted.

\section{Strengths and limitations of this study}

- This study is the first to quantify the association between public health-recommended physical activity volume and concussion risk using prospectively collected injury data.

- This investigation includes sensitivity analyses to facilitate transparency regarding the handling of missing and imputed data, and to quantify the impact on the findings.

- This study does not include a comprehensive capture of the physical activity recommendations as there was no measure of intensity and relies on the subjective report of physical activity by the participant as well as the team designate.

- The generalisability of the results of this investigation to the broader youth ice hockey population is limited by the lack of female youth ice hockey players and non-elite male ice hockey players aged 15-17 years.

\section{BACKGROUND}

The estimated cost of physical inactivity in Canada is approximately \$C10 billion, ${ }^{1}$ and the rate of inactivity among Canadian children and youth is staggering. An estimated $76 \%$ of Canadian children (aged 5-11 years) and youth (aged 12-17 years) participate in organised sport and physical activity $(\mathrm{PA}){ }^{2}$ Yet, only $9 \%-20 \%$ are reported as participating in 60 min of 'moderate' (ie, 3-4 metabolic equivalents METs) to 'vigorous' (ie, 7 METs) daily PA recommended by the Canadian Society of Exercise Physiology, the Public Health Agency of Canada and their collaborative partners. ${ }^{2-4}$ Although PA participation can improve health outcomes, it is also associated with increased injury risk, which can hinder or disrupt lifelong PA engagement. ${ }^{5}$ There is a significant body of evidence to suggest that PA may contribute to injury risk reduction in paediatric populations. ${ }^{6-8}$ There is an absence of literature, however, regarding 
the relationship between public health PA recommendations and injury, in any population. ${ }^{9}$

Identifying modifiable determinants of concussion is key to primary concussion prevention. There are two known studies that explore PA in this context, ${ }^{910}$ and only one which included paediatric participants. ${ }^{9}$ Hislop et al examined the injury prevention efficacy of a $20 \mathrm{~min}$ movement control programme among over 3000 English youth rugby players aged $14-18$ years, ${ }^{11}$ a sport with a high incidence of concussion in this age group. ${ }^{12}$ The authors reported that teams who engaged in a 20 min coach-delivered warm up programme with feedback focused on balance, plyometrics, cutting and rugby-specific skills had approximately 29\%-59\% fewer concussions over the season than teams who received a control programme (ie, dynamic stretch, controlled wrestling, mobility/speed, no feedback). ${ }^{11}$ Ice hockey is a popular sport among young Canadians, with 254504 registrants between the ages of 11 and 17 years. ${ }^{13}$ Concussions comprise up to $38.5 \%$ of all injuries in this age group. ${ }^{14-16}$ The association between Canadian PA recommendations and concussion rates in youth ice hockey is currently unknown.

\section{METHODS}

\section{Study objective}

The objective of this study was to explore the association between meeting the PA volume recommendations and concussion rates in ice hockey players aged $11-17$ years.

\section{Study design and sample acquisition}

This investigation analysed data pooled from open prospective injury surveillance cohort studies conducted at the University of Calgary Sport Injury Prevention Research Centre between 2011 and 2015. The studies aimed to identify concussion risk factors, monitor developmental and postconcussion changes in physical and cognitive function, and evaluate body checking policy as an injury prevention strategy.

All players enrolled in the Elite Hockey Concussion Study (Ethics ID: E-24026), the Safe to Play Study (S2P) (Ethics ID: REB-14-2209) or the Alberta cohort of the Alberta Program in Youth Sport and Recreational Injury Prevention Program Hockey Research Study (CRIO) (Ethics ID: E-20252 and REB-14-0348) were eligible for inclusion in this investigation. Consent was obtained from each player and their parent/guardian.

While it was possible for players to have been simultaneously enrolled in both S2P and CRIO, they were given a common study ID to avoid data duplication. S2P was a 5-year longitudinal study. If an individual was participating in S2P, only the data from their first year of study enrolment was considered. Players were excluded if they did not complete the 6-week PA history questionnaire, if they did not provide practice and/or game participation exposure hours, or if they reported sustaining an injury or time loss due to injury within 6 weeks of study entry. The paucity of concussed female players who met the inclusion criteria led to the subsequent exclusion of female players from this investigation.

\section{Participant involvement}

Participants were not involved in development of the research question, study design, recruitment or conduction of this investigation.

\section{Definitions and analytical design}

Players were asked to complete a baseline questionnaire with demographic and medical history information, as well as a retrospective 6-week history of their PA engagement on study entry. Players in the 2011 and 2013 cohorts completed the Physical Activity History Questionnaire (PAHQ) (online supplementary file 1), which was replaced in 2014-2015 with the Activity History Questionnaire (AHQ) (online supplementary file 2).

The product of the hours per week and the number of weeks was calculated to provide an estimate of 6-week total physical education (PE) participation. For players who completed the PAHQ, the hours for extracurricular sports were summed, and then multiplied by 6 to produce an estimate of 6-week total extracurricular sport participation. For those players who completed the AHQ the product of the hours per week and number of weeks was calculated for each sport. The hours for all sports were then summed to produce an estimate of 6-week total extracurricular sport participation. The 6-week PE participation and the 6-week extracurricular sport participation were summed to calculate 6 -week total PA volume. The 6 -week total PA volume was dichotomised at 42 hours to classify players according to whether or not they met the PA volume recommendations for the 6 weeks prior to study entry (ie, 42 hours or more). ${ }^{4}$

Players who were missing the hours per week and number of weeks of PE participation were assumed to not have had PE classes in the 6 weeks prior to study entry. The Alberta policy mandate of 5 hours of PE per week was used as a maximum cap for reported PE participation as well as to impute in the event that a player's hours per week of PE participation were missing, but the number of weeks was provided. ${ }^{17}{ }^{18}$ In the event that the number of weeks was missing, and the hours per week were provided, the number of weeks was imputed as the number of weeks from the first week of September in the study year to the date of the preseason questionnaire completion, to a maximum of 6 weeks. Players with 6-week total PA volumes of more than 186 hours were flagged as having invalid PA responses and excluded.

Players with suspected concussions were referred to a study sport medicine physician for assessment, diagnosis and management in accordance with the most recent International Conference on Concussion in Sport (ICCS) consensus statement at the time of study entry. ${ }^{19} 20$ Players who chose to seek medical attention from non-study physicians were asked to provide a doctor's note verifying their diagnosis. The number of medically diagnosed concussions for each player was 
recorded. If a medically diagnosed concussion occurred during a period in which no participation exposure data were collected for that player, it was excluded from the analyses.

Team designates were asked to complete weekly exposure sheets that were used to estimate players' participation in on-ice hockey practices and games. Team-specific variables (eg, session date, session type, duration) and player-specific variables (eg, level of participation) were recorded. Team designates were instructed to assign full participation to individuals who were present and able to participate in $75 \%$ or more of a session. Individuals who were able to participate in $<75 \%$ of a session were assigned partial participation. No participation was assigned to individuals who were absent, or present but unable to participate. If a player was recorded as having reduced participation (ie, partial or none), the team designates were instructed to provide a reason (eg, injury, illness, other).

Players with missing or systematically incomplete participation exposure data (eg, the team designate only provided game participation hours) were excluded. Players who were recorded as partial participation were entered at $50 \%$ of the duration for that session. The imputation protocol was developed in consultation with the Data Management team lead (LP-D) and applied to the participation exposure data across the three studies. ${ }^{21}$ The imputation of session duration was based on league-based normative practice (ie, 60 min) or game durations (ie, $75 \mathrm{~min}$ ), as appropriate. The imputation of missing participation codes was based on individual player pattern of participation before and after the missing date.

\section{Statistical analyses}

Data from each cohort were entered and stored in StudyTRAX, ${ }^{22}$ Research Electronic Data Capture ${ }^{23}$ or Microsoft Excel (2011), then merged, processed and analysed for the purposes of this investigation using STATA V.12.1. ${ }^{24}$ Descriptive statistics (ie, frequencies and proportions for categorical variables; means, 95\% CI, medians and IQRs for numerical variables) were calculated for player characteristics. Incidence rates (IRs) and 95\% CI were calculated for outcome variables. Unadjusted concussion IRs and 95\% CI were estimated based on the number of medically diagnosed concussions per 1000 participation hours. The association between meeting the PA volume recommendations (yes/no) and concussionrate are represented by concussion IR ratios (IRRs) and 95\% CI, which were calculated via multivariable Poisson regression modelling . Effect modification and confounding by age group (Pee Wee/Bantam/Midget), competition level (elite (top $30 \%$ by division of play)/non-elite (lower $70 \%$ by division of play)), and previous history of concussion (PHC) (yes/no) were evaluated using stepwise backward elimination. The covariates were modelled separately, as the frequency and distribution of concussions

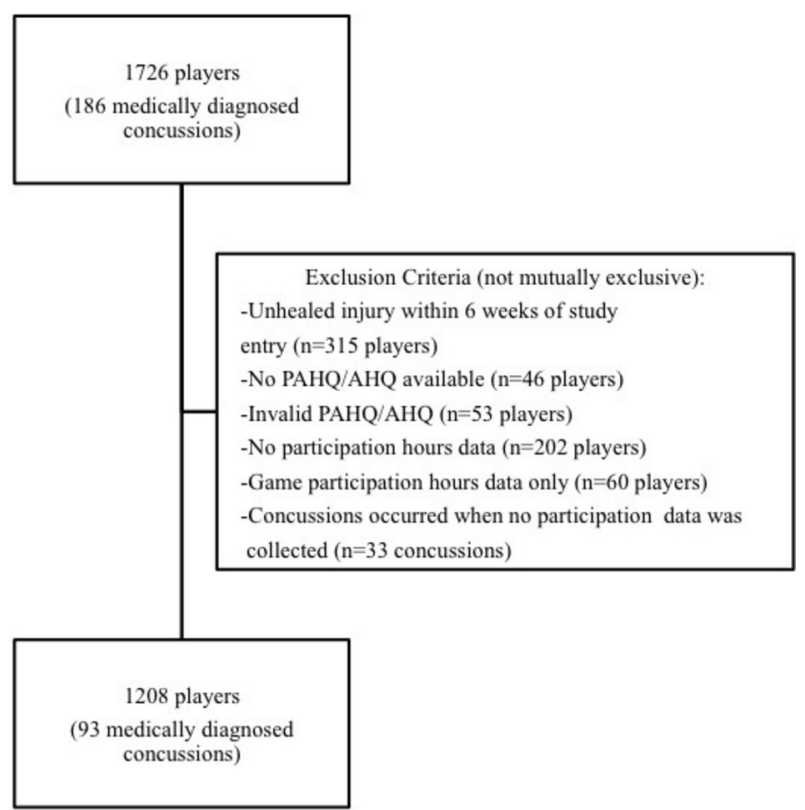

Figure 1 Participant exclusion flow chart. AHQ, Activity History Questionnaire; PAHQ, Physical Activity History Questionnaire.

did not support the inclusion of multiple covariates into a single model. Interaction between covariates was not evaluated. Models were adjusted for clustering by team and offset by participation hours. The $p$ value was set at $\alpha<0.05$, and all hypothesis testing was two sided. Point estimates where the $95 \%$ CI did not cross the null (ie, $1.00)$ were considered significant. Sensitivity analyses were conducted to evaluate the influence of imputed PA and participation exposure data on the findings.

\section{RESULTS}

A total of 1726 male ice hockey players were eligible for this investigation, with 162 players sustaining 186 medically diagnosed concussions. The application of the exclusion criteria resulted in a final dataset of 1208 players, including 93 individuals who sustained medically diagnosed concussions (figure 1).

Player characteristics are summarised in table 1.

The unadjusted concussion rate for included players was $0.97 / 1000$ participation hours (95\% CI 0.78 to 1.19). Outcome variables are summarised in table 2 by age group, PHC and competition level. No player sustained more than one medically diagnosed concussion during their included study period. Six of the 93 individuals who sustained a concussion $(6.45 \%)$ were not managed by study staff (Pee Wee, has a PHC, did not meet the PA recommendations $(\mathrm{n}=1)$; Midget, has a PHC, met the PA recommendations $(n=1)$; Midget, no concussion history, met the PA recommendations $(\mathrm{n}=3)$; Midget, no concussion history, did not meet the PA recommendations $(n=1))$. Approximately $68.21 \%$ of players provided a fully complete PA questionnaire; the remaining players' PA questionnaires contained 
Table 1 Player characteristics by concussion and physical activity (PA) status

\begin{tabular}{|c|c|c|c|c|c|}
\hline \multirow[b]{3}{*}{ Frequency (\%) } & \multicolumn{2}{|l|}{ Concussed (n=93) } & \multicolumn{2}{|c|}{ Not concussed $(n=1115)$} & \multirow[b]{3}{*}{ Total $(n=1208)$} \\
\hline & \multicolumn{4}{|c|}{ PA volume recommendations } & \\
\hline & $\begin{array}{l}\text { Met } \\
(n=59)\end{array}$ & $\begin{array}{l}\text { Not met } \\
(n=34)\end{array}$ & $\begin{array}{l}\text { Met } \\
(n=839)\end{array}$ & $\begin{array}{l}\text { Not met } \\
(n=276)\end{array}$ & \\
\hline \multicolumn{6}{|l|}{ Enrolment year } \\
\hline 2011-2012 & $36(61.02)$ & $11(32.35)$ & 277 (33.02) & $44(15.94)$ & 368 (30.47) \\
\hline 2013-2014 & $13(22.03)$ & $11(32.35)$ & $396(47.20)$ & $130(47.10)$ & $550(45.53)$ \\
\hline 2014-2015 & $10(16.95)$ & $12(35.30)$ & $166(19.78)$ & $102(36.96)$ & $290(24.00)$ \\
\hline \multicolumn{6}{|l|}{ Age group } \\
\hline Pee Wee (ages 11-12) & $12(20.34)$ & $11(32.35)$ & $376(44.82)$ & $127(46.02)$ & $526(43.54)$ \\
\hline Bantam (ages 13-14) & $22(37.29)$ & $16(47.06)$ & 281 (33.49) & 117 (42.39) & 436 (36.09) \\
\hline Midget (ages 15-17) & $25(42.37)$ & 7 (20.59) & $182(21.69)$ & $32(11.59)$ & $246(20.37)$ \\
\hline \multicolumn{6}{|l|}{ City } \\
\hline Calgary & $51(86.44)$ & $22(64.71)$ & $684(81.53)$ & $184(66.67)$ & $941(77.90)$ \\
\hline Edmonton & $8(13.56)$ & 12 (35.29) & $155(18.47)$ & $92(33.33)$ & $267(23.10)$ \\
\hline \multicolumn{6}{|l|}{ Competition level } \\
\hline Elite (upper 30\%) & $42(71.19)$ & $14(41.18)$ & $443(52.80)$ & $83(30.01)$ & $582(48.18)$ \\
\hline Non-elite (lower 70\%) & $17(28.81)$ & $20(58.82)$ & $396(47.20)$ & $193(69.93)$ & $626(51.82)$ \\
\hline \multicolumn{6}{|l|}{ Previous concussion history } \\
\hline Yes & $25(42.37)$ & $15(44.12)$ & 277 (33.02) & $70(25.36)$ & 387 (32.04) \\
\hline No & $32(54.24)$ & $17(50.00)$ & 559 (66.62) & $177(64.13)$ & 785 (64.98) \\
\hline Missing & $2(3.39)$ & $2(5.88)$ & $3(0.36)$ & $29(10.51)$ & $36(2.98)$ \\
\hline $\begin{array}{l}\text { Median days since most recent } \\
\text { concussion at study entry } \\
\text { (IQR) }\end{array}$ & $633.5(270-1508.5)$ & 748 (243-1738) & 589 (311-1061) & 715 (359-1179) & 635 (313-1195) \\
\hline
\end{tabular}

incomplete data that were subsequently imputed. Approximately $4.43 \%$ of the participation data were incomplete and subsequently imputed. Sensitivity analyses indicated that the use of imputed data did not influence the interpretations of the regression analyses findings (tables $3-5$ ).

Players who completed the PAHQ reported engaging in a median of 60 (IQR 42-84) hours in the 6 weeks prior to study entry. Players who completed the AHQ reported engaging in a median of 57 (IQR 38-83) hours in the 6 weeks prior to study entry. Approximately $65.05 \%$ of players who sustained concussions, and $75.34 \%$ of players who did not sustain concussions reported meeting the Canadian PA volume recommendations for children and youth of 1 hour daily in the 6 weeks prior to study entry (ie, 42 hours over 6 weeks).

The association between meeting the PA volume recommendations and concussion rate was modified by age group (table 3$)^{25}$ and competition level (table 4). ${ }^{25}$

The concussion rate among male Pee Wee ice hockey players who did not meet the PA volume recommendations was 2.94 (95\% CI 1.30 to 6.64) times the concussion rate of male Pee Wee ice hockey players who met the PA volume recommendations. Male Bantam ice hockey players who did not meet the PA volume recommendations had 2.18 (95\% CI 1.21 to 3.93 ) times the concussion rate of male Bantam ice hockey players who met the PA volume recommendations. The concussion rate in male Midget ice hockey players who did not meet the PA volume recommendations was not significantly different than male Midget ice hockey players who met the PA volume recommendations (IRR 1.37, $95 \%$ CI 0.73 to 2.56 ).

The concussion rate among non-elite Pee Wee and Bantam male ice hockey players who did not meet the PA volume recommendations was 2.45 (95\% CI 1.33 to 4.51) times the concussion rate in non-elite players who met the PA volume recommendations. The concussion rate in elite male Pee Wee and Bantam ice hockey players who did not meet the PA volume recommendations was not significantly different than elite players who met the PA volume recommendations (IRR 2.24, 95\% CI 0.99 to 5.13). There was no evidence of confounding or effect modification by PHC (table 5).

\section{DISCUSSION}

The paradoxical relationship between PA and injury risk has been used to illustrate why sport injury prevention should be viewed as a public health issue, particularly in 


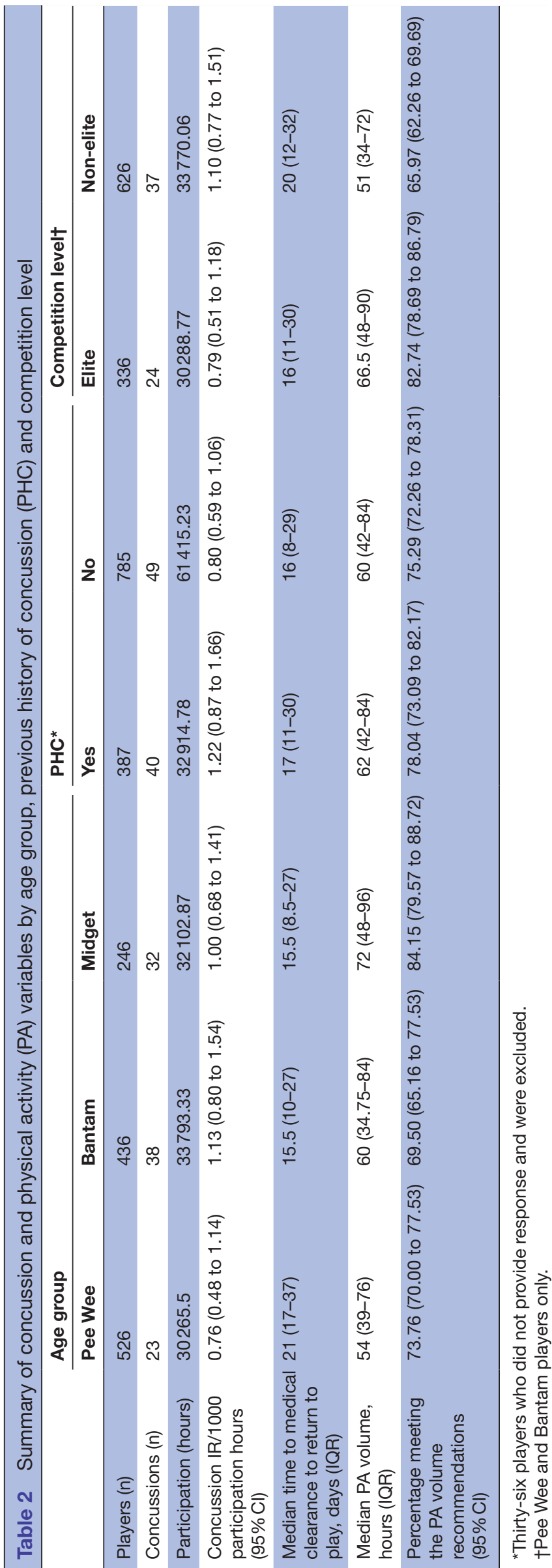

youth. ${ }^{5}$ The concussion rates of male Pee Wee, Bantam and non-elite ice hockey players ages 11-14years who did not report participating in an average of 1 hour of PA daily in the 6 weeks prior to study entry were more than twice the rates of their counterparts who reported averaging at least 1 hour of daily PA. These findings illustrate proof of concept for the inclusion of PA metrics in future primary concussion prevention research development, and intervention implementation initiatives.

The study population was comprised of individuals registered in extracurricular organised ice hockey, yet approximately one in four players reported not meeting the PA volume recommendations. This aligns with the findings of previous research, ${ }^{2-4}$ despite the fact that previous investigations were conducted with participants from the general population, rather than active sport participants. A review of Canadian child and youth PA indicators from 2005 to 2016 reported that positive change in structural PA indicators (eg, infrastructure availability, policy implementation and funding) did not translate into positive change in behavioural PA indicators (eg, organised sport, active transport, sedentary behaviour) ${ }^{26}$ Barnes and Tremblay suggest that a shift in focus towards targeting behavioural PA indicators, and that 'alternative approaches' may be required. ${ }^{26}$ The findings of this investigation, combined with previous research illustrating the detrimental impact of injury on team performance, ${ }^{27}$ provide points of convergence for public health and sport injury prevention stakeholders. Reframing the PA recommendations as performance enhancing, targeting organised youth ice hockey registrants and engaging coaches as PA champions are examples of strategies that represent a departure from current health promotion approaches that may warrant further study.

The role of previously evaluated variables such as concussion history, age group and competition level in this investigation was somewhat unexpected. Previous history of concussion has been a widely reported determinant of concussion in this population, whereas the impact of age group and competition level have been more equivocal. ${ }^{12-1628}$ In this investigation, age group and competition level appear to influence the relationship between PA volume recommendations and concussion rate, while concussion history does not. The results illustrate the value of multivariable analyses in the identification and contextualisation of injury determinants. ${ }^{29}$

The factors underpinning the association between the PA volume recommendations and concussion are unknown, but frameworks such as the Training-Injury Prevention Paradox model (T-IPP) may provide some insight. The T-IPP posits that training programmes resulting in sudden, rapid load increases are a critical determinant of non-contact soft-tissue injuries, rather than the volume of the training itself. ${ }^{30}$ Applied to this investigation, this premise would suggest that the PA recommendations were representative of participants' 
Table 3 Multivariable model: age group (adapted from Knol and Vander Weele) ${ }^{25}$

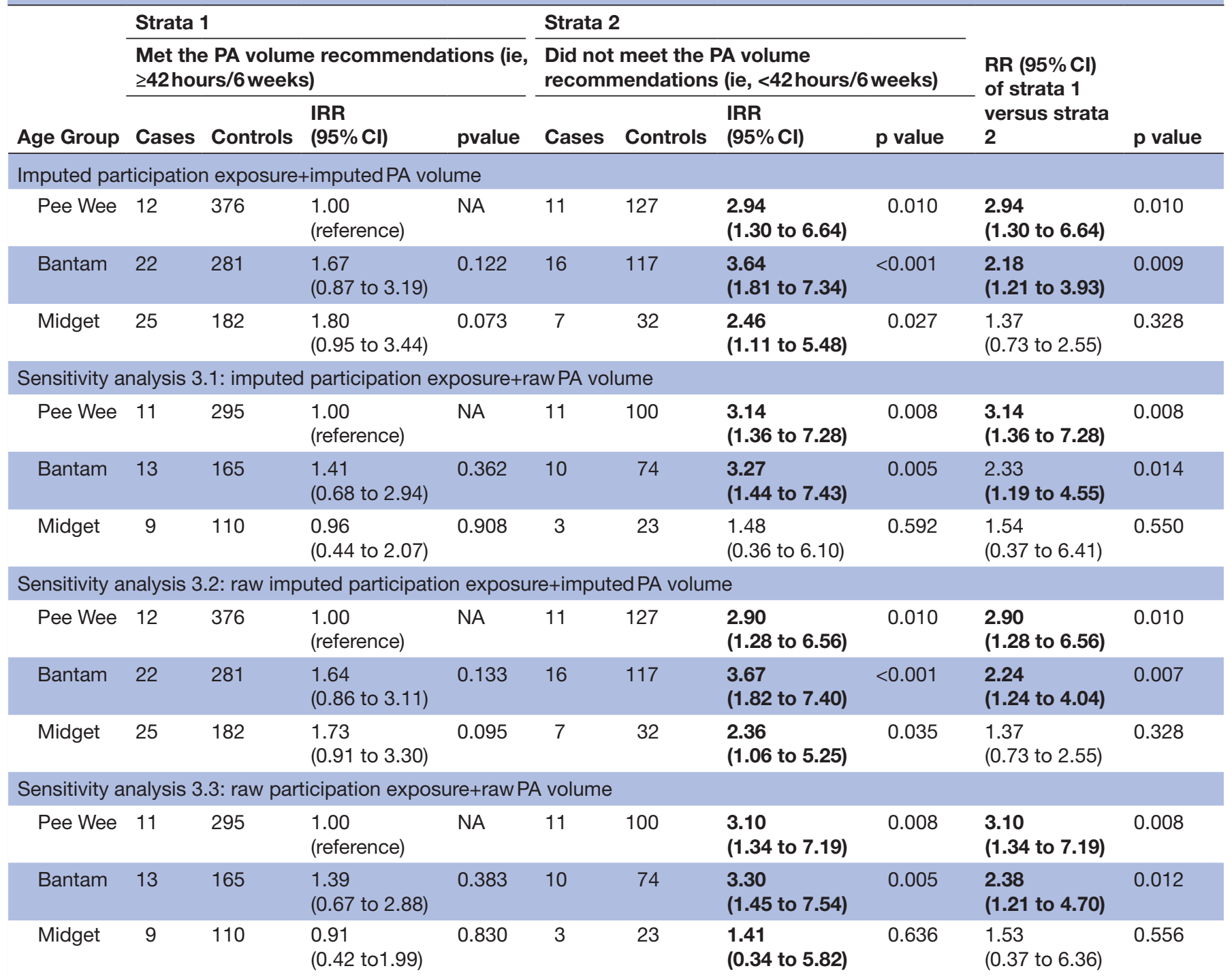

Bolded, significant finding (ie, $95 \% \mathrm{Cl}$ do not cross 1.00 ).

Final model: log odds (number of concussions) $=\beta_{0}+\beta_{1}(P A)+\beta_{2}$ (age group) $+\beta_{3}(P A \times a g e$ group), adjusted for clustering by team and offset by participation hours.

IRR, incidence rate ratio; NA, not applicable; PA, physical activity; RR, risk ratio.

preparedness to accept the hockey-related training demands they were exposed to during the study period. The T-IPP has not previously been applied in ice hockey populations, nor with concussion as the outcome of interest. Future research including measures of training volume and response to training volume would help to illustrate whether the tenets of the T-IPP could help explain the association between PA volume and concussion in youth ice hockey.

\section{Limitations}

This study is not without limitations. Missing, incomplete and potentially invalid data resulted in the exclusion of over 300 male youth ice hockey players who were included in the three prospective cohort studies, as well as the imputation of participation hours and PA volume. Additionally, the inclusion criteria for each cohort differed such that the role of known concussion determinants (eg, participation exposure to body checking) and the interaction between covariates could not be evaluated. The concussion incidence distribution resulted in age group and competition level strata that were underpowered, increasing the risk of type II error. Issues related to data pooling could be significantly reduced, if not resolved, in future studies specifically designed to address objectives related to PA and concussion risk. Technology-based injury surveillance systems could be used to identify skipped questions and invalid responses in real time, and reduce errors associated with multistep, paper-and-pen data collection and data entry. ${ }^{31-34}$ Research validating technology-based injury surveillance systems is needed to demonstrate their feasibility in community-based youth ice hockey 
Table 4 Multivariable model: competition level-Pee Wee and Bantam players only (adapted from Knol and Vander Weele) ${ }^{25}$

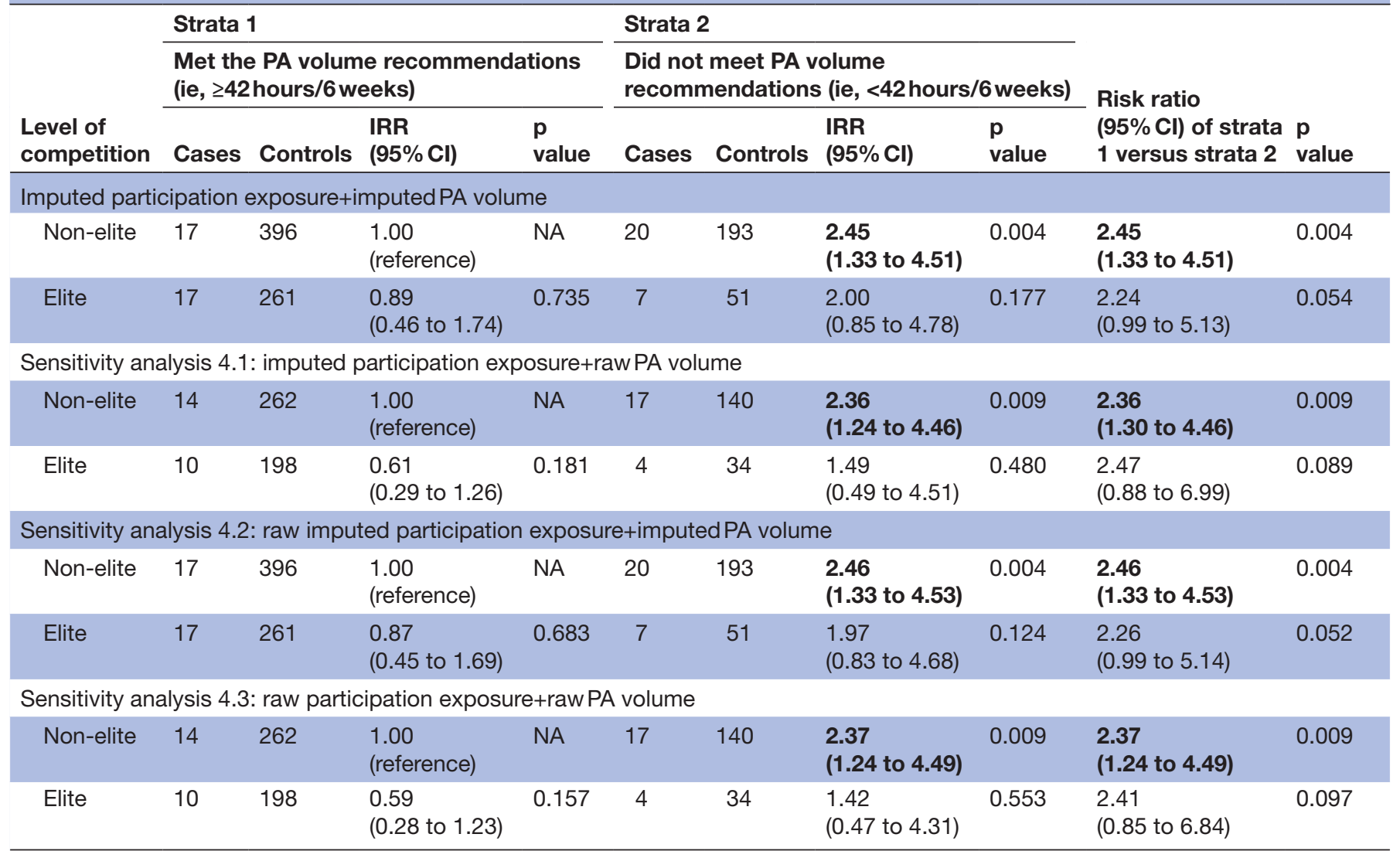

Bolded, significant finding (ie, $95 \% \mathrm{Cl}$ do not cross 1.00 ).

Final model: log odds (number of concussions) $=\beta_{0}+\beta_{1}(P A)+\beta_{2}$ (competition level) $+\beta_{3}(P A \times c o m p e t i t i o n$ level), adjusted for clustering by team and offset by participation hours.

IRR, incidence rate ratio; NA, not applicable; PA, physical activity.

populations. These findings-particularly competition level, where the point estimates of each stratum were very close, and the CI in the elite strata just barely crossed the null-need to be reproduced in future research with appropriate power.

PA volume estimates were based on self-report, thus were susceptible to recall and social desirability biases. ${ }^{35}$ These biases would overestimate PA volume, regardless of whether or not a player had sustained a concussion. This would result in non-differential misclassification error, and bias the results towards the null. Future studies that use more objective measures of PA volume, or measures with greater psychometric rigour, will be less susceptible to these biases and improve the precision of effect size of PA volume as a concussion risk factor in youth ice hockey players.

Table 5 Multivariable model: previous concussion history (PHC)

\begin{tabular}{|c|c|c|c|c|}
\hline & $\begin{array}{l}\text { Crude risk ratio } \\
(95 \% \mathrm{Cl})\end{array}$ & $p$ value & $\begin{array}{l}\text { Risk ratio adjusted } \\
\text { for } \mathrm{PHC}^{*}(95 \% \mathrm{Cl})\end{array}$ & p value \\
\hline Imputed participation exposure+imputed PA volume & 2.05 (1.40 to 3.01$)$ & $<0.001$ & $2.17(1.49$ to 3.18$)$ & $<0.001$ \\
\hline $\begin{array}{l}\text { Sensitivity analysis 5.2: raw participation exposure+imputed } \\
\text { PA volume }\end{array}$ & $2.07(1.41$ to 3.04$)$ & $<0.001$ & $2.18(1.49$ to 3.18$)$ & $<0.001$ \\
\hline
\end{tabular}

Bolded=significant finding (ie, $95 \% \mathrm{Cl}$ do not cross 1.00 ).

Final model: log odds (number of concussions) $=\beta_{0}+\beta_{1}(\mathrm{PA})$, adjusted for clustering by team and offset by participation hours.

${ }^{*}$ Thirty-six players who did not provide response regarding $\mathrm{PHC}$ were excluded.

PA, physical activity. 
Suspected concussions that were not confirmed by a medical physician were not included in this investigation. Individuals who sustained a concussion may have been erroneously classified as not having sustained a concussion. This may have occurred regardless of whether or not the PA volume recommendations were met, resulting in non-differential misclassification errors that bias the results towards the null. It is possible the six participants managed by physicians external to the study did not meet the ICCS concussion definition used to identify concussions in this study, as the diagnostic criteria of external physicians is unknown. The distribution of these participants would result in differential misclassification errors that would bias the findings towards the null in the age group and concussion history analyses. As only one participant was included in the competition level analyses, any bias towards the null resulting from the differential misclassification error would likely be minimal.

While these findings are compelling, this investigation does not include a comprehensive capture of PA. PA involving transportation (eg, biking to school), occupation (eg, lifeguarding) or errands and chores (eg, dog walking) was not captured. The concussion risk associated with PA as a continuous variable cannot be extrapolated from these findings. PA volume in isolation is not a proxy for physical fitness, so the results of this investigation cannot be used to infer a relationship between concussion risk and the participants' physical fitness. Future research should consider more comprehensive measures of PA volume, the inclusion of measures of PA intensity, duration and distribution, as well as metrics of sedentary behaviour.

The absence of female youth ice hockey players and non-elite male Midget players, as well as limiting the recruitment areas to large Canadian cities in a single province limits the generalisability of these findings to the broader youth ice hockey community. The results of this investigation, however, could be used to calculate a priori sample size estimates for future research with more diverse representations of youth ice hockey.

\section{CONCLUSION}

Male Pee Wee, Bantam, and non-elite level ice hockey players who did not meet the Canadian PA volume recommendations had rates of concussion more than twice that of their counterparts who met the Canadian PA volume recommendations. This relationship was not observed among Midget or elite players. Concussion history was not found to significantly influence the relationship between PA volume recommendations and concussion rates in male ice hockey players. This is the first known investigation to evaluate the implications of adherence to public health-driven PA volume recommendations from a sport injury prevention perspective. Despite its limitations, the findings from this investigation suggest that further research evaluating the association of PA and concussion risk and the implications for public health PA recommendations in a sport injury prevention context is warranted.

Author affiliations

${ }^{1}$ Sport Injury Prevention Research Centre, Faculty of Kinesiology, Calgary, Alberta, Canada

2Department of Physical Therapy, University of Toronto, Toronto, Ontario, Canada ${ }^{3}$ Faculty of Environmental Design, University of Calgary, Calgary, Alberta, Canada ${ }^{4}$ Neurosciences Program, Alberta Children's Hospital, Calgary, Alberta, Canada ${ }^{5}$ Department of Psychology, Faculty of Arts, University of Calgary, Calgary, Alberta, Canada

${ }^{6}$ Cumming School of Medicine, Alberta Children's Hospital Research Institute, University of Calgary, Calgary, Alberta, Canada

${ }^{7}$ Departments of Pediatrics and Clinical Neurosciences, Cumming School of Medicine, University of Calgary, Calgary, Alberta, Canada

${ }^{8}$ Community Health Sciences, Cumming School of Medicine, University of Calgary, Calgary, Alberta, Canada

${ }^{9}$ Allied Health Department, University Health Network-Toronto Western Hospital, Toronto, Ontario, Canada

Acknowledgements Thank you to Drs. Carly McKay, Andrea Jubinville, Kathryn Schneider, Marty Mrazik, Connie Lebrun and Brian Benson, Nicole Lemke, Kirsten Taylor, Hockey Calgary, Hockey Edmonton, the research coordinators and study staff, as well as all the players and their families, therapists, trainers, coaches for their support of, and participation in this work.

Contributors TAB conceived of the study question, compiled, processed and analysed the data, and wrote the original version of the manuscript as part of her doctoral thesis. The original cohorts used to extract the population for this investigation were funded by grants on which CAE was a principal investigator, and PKD-B and BLB were coinvestigators. CAE (doctoral supervisor), as well as PKD-B and BLB (doctoral committee members) reviewed, and provided expertise to the study proposal and protocol development. LP-D was consulted in the development of the data processing and imputation protocol, and provided expertise with respect to the data analyses. All authors reviewed and approved of the final manuscript.

Funding This study is part of the PhD work of TAB, which was partially funded by Talisman Energy Fund in Support of Healthy Living and Injury Prevention through the Alberta Children Hospital Research Institute. BLB receives salary funding from the Canadian Institutes for Health Research (CIHR) Embedded Clinician Researcher Salary Award. CAE holds the Chair in Pediatric Rehabilitation through the Alberta Children's Hospital Foundation. The Safe to Play study was funded by the Hotchkiss Brain Institute, and the Institute for Neurosciences, Mental Health, and Addiction Institute of the Canadian Institutes for Health Research (grant ID: TM2- 127049). The Alberta cohort of the Alberta Program in Youth Sport and Recreational Injury Prevention Program Hockey Research Study was funded by Alberta InnovatesHealth Solutions (grant ID: 201201160/3685). Additional monetary support was provided by the McCarthy Tetrault Award, the Max Bell Foundation and the Alberta Children's Hospital Research Institute (Alberta Children's Hospital Foundation). The Sport Injury Prevention Research Centre at the University of Calgary is one of the International Research Centres for Prevention of Injury and Protection of Athlete Health supported by the International Olympic Committee.

Competing interests Brooks reports and receives royalties for the sales of the Pediatric Forensic Neuropsychology textbook (2012, Oxford University Press) and three pediatric neuropsychological tests (Child and Adolescent Memory Profile (ChAMP, Sherman and Brooks, 2015, PAR), Memory Validity Profile (MVP, Sherman and Brooks, 2015, PAR) and Multidimensional Everyday Memory Ratings for Youth (MEMRY, Sherman and Brooks, 2017, PAR)). He has previously received in-kind support (free test credits) from the publisher of the computerised cognitive test (CNS Vital Signs, Chapel Hill, North Carolina). He acknowledges salary funding from the Canadian Institutes for Health Research (CIHR) Embedded Clinician Researcher Salary Award to study outcomes from concussion. TAB, PKD-B, LP-D and CAE have no competing interests to disclose.

Patient consent Obtained.

Ethics approval Ethics approval was obtained from the University of Calgary Conjoint Health Research Ethics Board for each study.

Provenance and peer review Not commissioned; externally peer reviewed.

Data sharing statement We do not have a data sharing agreement. The results of this study will be publicly available. 
Open access This is an open access article distributed in accordance with the Creative Commons Attribution Non Commercial (CC BY-NC 4.0) license, which permits others to distribute, remix, adapt, build upon this work non-commercially, and license their derivative works on different terms, provided the original work is properly cited, appropriate credit is given, any changes made indicated, and the use is non-commercial. See: http://creativecommons.org/licenses/by-nc/4.0/.

\section{REFERENCES}

1. Krueger $\mathrm{H}$, Turner D, Krueger J, et al. The economic benefits of risk factor reduction in Canada: tobacco smoking, excess weight and physical inactivity. Can J Public Health 2014;105:69-78.

2. ParticipACTION. The 2016 ParticipACTION Report Card on Physical Activity for Children and Youth, ParticipACTION, ed. 2016. http:// www.participaction.ca.

3. Tremblay MS, Leblanc AG, Janssen I, et al. Canadian sedentary behaviour guidelines for children and youth. Appl Physiol Nutr Metab 2011:64:65-71.

4. Tremblay MS, Warburton DE, Janssen I, et al. New Canadian physical activity guidelines. Appl Physiol Nutr Metab 2011;36:36-46.

5. Emery CA. Injury prevention in paediatric sport-related injuries: a scientific approach. Br J Sports Med 2010;44:64-9.

6. Rössler R, Donath L, Verhagen E, et al. Exercise-based injury prevention in child and adolescent sport: a systematic review and meta-analysis. Sports Med 2014;44:1733-48.

7. Soomro N, Sanders R, Hackett D, et al. The Efficacy of Injury Prevention Programs in Adolescent Team Sports: A Meta-analysis. Am J Sports Med 2016;44:2415-24.

8. Emery CA, Roy TO, Whittaker JL, et al. Neuromuscular training injury prevention strategies in youth sport: a systematic review and metaanalysis. Br J Sports Med 2015;49:865-70.

9. Janssen I, Leblanc AG. Systematic review of the health benefits of physical activity and fitness in school-aged children and youth. Int J Behav Nutr Phys Act 2010;7:40.

10. Attwood MJ, Roberts SP, Trewartha G, et al. Efficacy of a movement control injury prevention programme in adult men's community rugby union: a cluster randomised controlled trial. Br J Sports Med 2018;52:368-74.

11. Hislop MD, Stokes KA, Williams S, et al. Reducing musculoskeletal injury and concussion risk in schoolboy rugby players with a preactivity movement control exercise programme: a cluster randomised controlled trial. Br J Sports Med 2017;51:1140-6.

12. Pfister T, Pfister K, Hagel B, et al. The incidence of concussion in youth sports: a systematic review and meta-analysis. $\mathrm{Br} J$ Sports Med 2016;50:292-7.

13. Canada H. Annual Report, 2015.

14. Emery CA, Kang J, Shrier I, et al. Risk of injury associated with body checking among youth ice hockey players. JAMA 2010;303:2265-72.

15. Emery C, Kang J, Shrier I, et al. Risk of injury associated with bodychecking experience among youth hockey players. CMAJ 2011;183:1249-56.

16. Black AM, Macpherson AK, Hagel BE, et al. Policy change eliminating body checking in non-elite ice hockey leads to a threefold reduction in injury and concussion risk in 11- and 12-year-old players. Br J Sports Med 2016;50:55-61.
17. Education CBo. Promoting physical activity and emotional well-being in school communities: Edmonton Board of Education. 2013 http:// www.epsb.ca/ourdistrict/policy/f/fbe-ar/17-FBE.ARHealthandWelln essofStaffandStudents.pdf (cited 2016accessed 10 Mar 2016).

18. Education CBo.. Phyiscal Education: Calgary Board of Education. 2015 http://schools.cbe.ab.ca/cbe-learn/courses-physed.html (accessed March 10 2016).

19. McCrory P, Meeuwisse W, Johnston K, et al. Consensus statement on concussion in sport - The 3rd international conference on concussion in sport held in Zurich, November 2008. Pm $R$ 2009;1:406-20.

20. McCrory P, Meeuwisse W, Aubry M, et al. Consensus statement on Concussion in Sport - The 4th International Conference on Concussion in Sport held in Zurich, November 2012. Phys Ther Sport 2013;14:e1-e13.

21. Blake TA. Physical Activity and Concussion Outcomes in Youth Ice Hockey Players. Canada: University of Calgary, 2016.

22. ScienceTRAX. StudyTRAX. Macon, Georgia: ScienceTRAX, 2011.

23. Harris PA, Taylor R, Thielke R, et al. Research electronic data capture (REDCap)-a metadata-driven methodology and workflow process for providing translational research informatics support. J Biomed Inform 2009;42:377-81.

24. Stata Statistical Software: Release 12 [program]. College Station, Texas: StataCorp LP, 2011.

25. Knol MJ, VanderWeele TJ. Recommendations for presenting analyses of effect modification and interaction. Int J Epidemiol 2012;41:514-20.

26. Barnes JD, Tremblay MS. Changes in indicators of child and youth physical activity in Canada, 2005-2016. Can J Public Health 2017;107:586-e89.

27. Emery CA, Kang J, Schneider KJ, et al. Risk of injury and concussion associated with team performance and penalty minutes in competitive youth ice hockey. Br J Sports Med 2011;45:1289-93.

28. Emery CA, Hagel B, Decloe M, et al. Risk factors for injury and severe injury in youth ice hockey: a systematic review of the literature. Inj Prev 2010;16:113-8.

29. Bittencourt NF, Meeuwisse WH, Mendonça LD, et al. Complex systems approach for sports injuries: moving from risk factor identification to injury pattern recognition-narrative review and new concept. Br J Sports Med 2016:1309-14.

30. Gabbett TJ. The training-injury prevention paradox: should athletes be training smarter and harder? Br J Sports Med 2016;50:273-80.

31. Schiff MA, Mack CD, Polissar NL, et al. Soccer injuries in female youth players: comparison of injury surveillance by certified athletic trainers and internet. J Athl Train 2010;45:238-42.

32. Clarsen B, Myklebust G, Bahr R. Development and validation of a new method for the registration of overuse injuries in sports injury epidemiology: the Oslo Sports Trauma Research Centre (OSTRC) overuse injury questionnaire. Br J Sports Med 2013;47:495-502.

33. Nilstad A, Bahr R, Andersen TE. Text messaging as a new method for injury registration in sports: a methodological study in elite female football. Scand J Med Sci Sports 2014;24:243-9.

34. Ekegren CL, Gabbe BJ, Finch CF. Sports Injury Surveillance Systems: A Review of Methods and Data Quality. Sports Med 2016;46:49-65.

35. Adamo KB, Prince SA, Tricco AC, et al. A comparison of indirect versus direct measures for assessing physical activity in the pediatric population: a systematic review. Int J Pediatr Obes 2009;4:2-27. 